\title{
ENGLISH LANGUAGE LEARNERS IN INTRODUCTORY STATISTICS: LESSONS LEARNED FROM AN EXPLORATORY CASE STUDY OF TWO PRE-SERVICE TEACHERS
}

\author{
LAWRENCE M. LESSER \\ The University of Texas at El Paso \\ Lesser@utep.edu \\ MATTHEW S. WINSOR \\ Illinois State University \\ mwinsor@ilstu.edu
}

\begin{abstract}
Despite the rapidly growing population of English language learners in U.S. colleges and schools, very little research has focused on understanding the challenges of English language learners specifically in statistics education. At a university near the United States-México border, the authors conducted an exploratory qualitative case study of issues of language in learning statistics for pre-service teachers whose first (and stronger) language is Spanish. The two strongest findings that emerged from cross-case analysis of the interviews were the importance of the role of context (the setting in which information is communicated) and the confusion among registers (subsets of language). This paper overviews and synthesizes relevant literature and offers resources and recommendations for teaching and future research.
\end{abstract}

Keywords: Statistics education research; Language; Spanish; Teacher education

\section{INTRODUCTION}

According to Goldenberg (2008), the fraction of United States public school K-12 students who are English language learners has gone from 1 in 20 (in 1990) to 1 in 9 (today), and is projected to be 1 in 4 in another twenty years. Though not as dramatically, the proportion of college students who are English language learners is also growing. An English language learner (ELL) speaks English "with enough limitations that he or she cannot fully participate in mainstream English instruction" (ibid, p. 10). The term ELL has been in use as early as 1994 (e.g., Lacelle-Peterson \& Rivera, 1994), and is generally viewed as a positive alternative to "Language Minority" or (the U.S. Federal term) "Limited English Proficient." Other terms in the literature include English as a Second Language (ESL) student or Culturally and Linguistically Diverse (CLD) learner. Goldenberg reports that ELLs in the United States come from over 400 different language backgrounds, but $80 \%$ are Spanish speakers, and so this specific type of ELL will be the main focus of this paper. In this paper, the term non-ELL denotes someone who has the fluency of a native English speaker.

Because language is an important factor in ELL mathematics performance, and because there is a mathematics performance gap between ELLs and non-ELLs, it becomes

Statistics Education Research Journal, 8(2), 5-32, http://www.stat.auckland.ac.nz/serj

(C) International Association for Statistical Education (IASE/ISI), November, 2009 
all the more important to gain more insight into how ELLs learn (Chen \& $\mathrm{Li}, 2008$ ). Unfortunately, most teachers have not had substantial training in how to teach their content to ELLs (see Batt, 2008; Esch et al., 2005), and this may be exacerbated if a student's culture (including their status as an ELL) makes that student reluctant during class to ask for a concrete example or paraphrasing. Such students may temporarily stop listening to the instructor as they turn to ask a neighbor or they may just continue listening despite having missed crucial key words. In particular, students whose main prior or early education was in the lecture-driven, culturally formal system of México may be less likely to feel comfortable "interrupting" the flow of a professor's lecture to ask about a word's meaning. As Pappamihiel and Mihai (2006) note, "it is not unusual for ELLs to feign understanding so that they do not draw unwanted attention to themselves in class. Hence, content area teachers should question culturally appropriate 'signals' (e.g., nodding) that indicate the ELLs are paying attention and understanding” (p. 41). On the other hand, professors must also guard against underestimating ELLs' understanding by misperceiving a student as hesitant and uncertain simply because of the student's intonation patterns (Moschkovich, 2007).

There is now much known (e.g., Fischer \& Perez, 2008) on what can help ELLs learn mathematics, including such strategies as building upon prior knowledge, cognates, brainstorming, and multiple meaningful contexts and learning strategies. Dale and Cuevas (1992) happen to use a statistics example in a teacher's script to model the strategy of building upon everyday language:

Give me a word or expression that tells where this number [the sum of scores divided by the number of scores] is in the distribution of scores. [The students offer words like 'middle' and 'center.'] I see we pretty much agree that this result of quotient is somewhere in the center of each distribution. We call this number a measure of central tendency. We know that the calculations we did had to do with the average of each of the distributions. Can someone give me a definition of 'average'? [The students give a number of plausible definitions.] In statistics, this average has a special name. It is called the mean. (pp. 343-344)

Another technique that can be adapted for statistics education is giving students key words to use in a sentence or giving them a "sentence frame" to fill in to "structure and scaffold understanding while giving ELLs the support that they need for speaking in front of their classmates" (Santa Cruz \& Sanchez-Gutiérrez, 2009, p. 4). An example of a sentence frame for hypothesis testing might be: "The $p$-value obtained was which is [less / greater] than our preset significance level of __ , and therefore we [reject / fail to reject] the null hypothesis that

Although statistics and mathematics professional and educational organizations have been enjoying increasing and high levels of collaboration in recent years, and where mathematics is a necessary part of the preparation to study statistics, the fact remains that there are ways in which statistics is not simply a branch of mathematics. One of several examples Cobb and Moore (1997) and Moore (1988) provide to support this latter claim is that observational and experimental data have very different interpretations but use the same mathematical models of statistical theory. Shaughnessy (1992) discusses how different foundational conceptions of probability or inference play out in teaching and research today (in a way that does not occur in mathematics). The distinctiveness of statistics is relevant because one or more of the ways in which statistics is different from mathematics could plausibly affect how ELL issues play out in a concrete way.

There have been some expository and didactic articles (e.g., Hubbard, 1991) specifically about ELLs learning statistics, but not with a sustained and comprehensive research focus. There have been a few studies about language issues in learning statistics 
(e.g., Kaplan, Fisher, \& Rogness, 2009; Lavy \& Mashiach-Eizenberg, 2009) or probability (e.g., Green, 1984), but these generally do not involve students learning in a second language. There have been a few research studies about the second language learners learning probability (Kazima, 2007; Phillip \& Wright, 1977), but these did not involve Spanish and probability is only a limited (and, in some ways, an increasingly deemphasized) part of the introductory statistics curriculum.

After stating the purpose of the study, this paper articulates theoretical considerations, describes methodology, and discusses the main emergent findings and the study's limitations. The paper then offers directions for future research and recommendations for teaching.

\section{PURPOSE}

This study aims for further insight into how ELLs encounter language in introductory statistics, including identifying particularly illuminating examples as well as what factors may interfere with ELLs distinguishing between everyday usage of a word and mathematical/statistical usage. Because of the dearth of research specifically on statistics learning for ELLs, it is not obvious whether these factors will play themselves out in the same way for ELLs as for non-ELLs. Nor is it obvious whether all recommendations for ELLs from, say, the mathematics education literature will transfer to statistics education without modification. To explore this specialized intersection, a team of researchers was formed whose collective scholarly backgrounds included expertise in statistics content, statistics education, mathematics education, and learning English as a second language. A secondary purpose of this study is to identify directions for future research in this new intersection of ELL and statistics education and also to articulate research-based implications for teaching that may address identified issues.

\section{THEORETICAL CONSIDERATIONS}

As students acquire a second language, two proficiencies emerge which Cummins (1992) calls Basic Interpersonal Communicative Skills (BICS) and Cognitive Academic Language Proficiency (CALP). BICS entails being able to communicate in everyday, context-embedded situations, whereas CALP is being able to communicate in complex decontextualized academic situations, where there are fewer environmental and nonverbal cues or representations. More nuances of decontextualization are articulated in Schleppegrell (2004).

The skills of BICS are more readily observed, such as clear pronunciation, grammar, and vocabulary knowledge, whereas CALP includes semantics and functional meaning in an academic, specialized context (Shuy, 1981). Although BICS may be acquired in 1-3 years, CALP may take 4-7 years (Cummins, 1992; Johnson, 2010). Collier (1987) notes that ELLs who arrive later in the United States have more difficulty acquiring the English needed to be successful in academic subjects.

Related to the distinction between BICS and CALP is the concept of register, which will facilitate further distinctions. A register is a subset of language used for a particular purpose. Just because someone learned statistics in one language and is conversationally fluent in another language, it does not mean they can communicate about statistics in that latter language. Moschkovich (2002), reinforcing the view of Halliday (1975) that ELLs learn academic content by making multiple meanings for words rather than only acquiring a list of words, states, "Unlike the notion of lexicon, the notion of register depends on the situational use of much more than lexical items and includes phonology, morphology, 
syntax, and semantics as well as non-linguistic behavior" (p. 194). Examples relevant to phonology (where pronunciation informs meaning) could include the words survey and estimate, whereas a morphology (pattern of word formation) example would be the related words random, randomized, and randomization.

One challenge ELLs face is that the academic meaning of a term may be the same as the everyday meaning, different from the everyday meaning, or not have an everyday counterpart at all. Navigating the academic language of statistics is challenging also for students whose first language is English (Garaway, 1994; Nolan, 2002; Ortiz, Cañizares, Batanero, \& Serrano, 2002; Rangecroft, 2002).

The most difficult of these three possibilities is arguably when the everyday and statistical meanings differ, and this claim is consistent with the findings of Lavy and Mashiach-Eizenberg (2009). The existence of these situations is acknowledged by Martynenko (2003) and by the American Statistical Association ([ASA], 2005), one of whose goals for introductory statistics is that "Students should recognize that words such as 'normal,' 'random,' and 'correlation' have specific meanings in statistics that may differ from common usage.” Similarly, Beyth-Marom, Fidler, and Cumming (2008) discuss 'correlation.' Another example is that students may not always be able to tell when the phrase "significant result" refers to statistical significance or practical significance. Gephart, Jr. (1988) discusses how the lay meaning of the term significant has even contributed to the overuse of statistical significance tests among economists. For a technology-related example, consider that the "MODE" button on the TI-73/83/84+ graphing calculator has nothing to do with the most frequent observation or a calculator command to produce it. Other examples are in Rumsey (2009).

A further challenge occurs when a word's statistical meaning differs not only from its everyday meaning, but also from its meaning in another academic context or register within CALP such as mathematics. For example, the word variation refers to a major theme in statistics (beyond any one specific measure of it, such as range or standard deviation), but the first academic context where a student heard the word variation was likely a high school algebra lesson on direct, inverse, or joint variation (e.g., $A=\pi r^{2}, I=$ $\mathrm{k} / d^{2}$, or $V=\pi r^{2} h$, respectively), all of which are deterministic relationships - that is, with no variation in the statistical sense.

As students read textbooks, they must rely heavily on their knowledge of vocabulary and linguistic conventions used to make texts explicit and self-contained (Schleppegrell, 2004). Language in traditional classrooms is more context-reduced (though perhaps somewhat less so in a statistics classroom than a mathematics classroom), so students have few contextual cues to help negotiate meaning. Even symbols (e.g., $N, p, \alpha$ ) can be used in more than one way within the realm of statistics.

The most important clue to deduce the meaning of a word or sentence is generally its context (Chastain, 1988) and when students find context meaningful, it increases their motivation to learn and communicate (Bourque \& Jacques, 1995). According to Cummins (1992), initial second language instruction that is context-embedded will prepare students for success in context-reduced situations. Context-embedded instruction has similar benefits for teaching ELLs mathematics (e.g., Goldenberg, 2008) and statistics is arguably a more natural vehicle for context-embedded instruction than mathematics, in light of the juxtaposition articulated by Cobb and Moore (1997). Context also has a major presence in the qualitative features of quantitative analysis described by Gephart, Jr. (1988) and Huberty (2000).

In addition to contextualization, ELL learning is also affected by prior content knowledge. Cummins (1992) posits a concept of underlying student proficiencies in academic subjects. These underlying proficiencies make possible the transfer of 
cognitive/academic skills across languages. If students learn a fact in a first language, they will be able to transfer that fact to their second language. ELLs may struggle learning the content in their second language if their academic knowledge is not sufficiently strong in their first language (Cummins, 1979; Fischer \& Perez, 2008).

\section{METHOD}

\subsection{SETTING}

The site of this research is a moderately large doctoral/research university located in a large city in the southwestern United States by the México border. Roughly $77 \%$ of the student population (and of the city) is Hispanic and about 10\% of the Hispanic student population is Mexican nationals who commute across the border to take courses. The mission of this university to provide its regional population access to quality higher education provides a compelling reason to conduct this study there, and the high proportion of Spanish-speaking ELLs makes the population an appropriate one to learn from because many parts of the country (and the world) are encountering rapid growth in this demographic group.

\subsection{PARTICIPANTS}

The call for participants asked for students who were native Spanish speakers and currently taking undergraduate mathematics or statistics classes at the aforementioned university. The researchers intended to do a case study of a small number of participants and were prepared to select them with purposeful sampling if an unduly large number of volunteers expressed interest in being in the study. However, due to the specialized nature of the target population, the very minimal compensation offered, and possibly also because of general reluctance such students may have in self-identifying and/or being part of a research study they may not fully understand, there were only two students who volunteered to participate within the established time frame and so both were selected without sampling. Fortunately, there was no attrition - the participants agreed to the initial interviews and all requests for follow-up interviews and member checking. Also, their particular backgrounds (which are detailed below) were consistent with the "typical case" type of sampling (Miles \& Huberman, 1994) and therefore sufficient to yield useful insights for this exploratory study. In particular, they were both Latinas (the modal gender and ethnicity at this university), they were both pre-service teachers, and they were similar in English language proficiency. Improved understanding of ELLs who are preservice teachers has particular importance for university instructors because one's pedagogical choices affect not only these students' learning, but also have the potential to influence how able these students will be to teach ELLs in their future classrooms. The two respondents are identified in this paper (and in transcripts) as S1 and S2.

S1 is a Latina who was taught through the end of eighth grade (which did not include algebra) in Spanish only and who rated herself a $2+$ or Advanced Plus on the ILR (Interagency Language Roundtable) and ACTFL (American Council on the Teaching of Foreign Languages) language scales, respectively, which state this interpretation: "Able to satisfy most work requirements and show some ability to communicate on concrete topics." At the start of the study, she was a senior mathematics major with a secondary minor in education and a pre-service high school teacher who had taken (1.5 years before the study) the same introductory statistics course S2 had just started. Both iterations of the course used a statistics literacy approach with the book by Utts (2005). 
S2 is a Latina who was taught in Spanish through the end of high school and who rated herself a 2 or Advanced on the ILR and ACTFL scales, respectively, which means "able to satisfy routine social demands and limited work requirements." At the beginning of the study, she was a junior, an education major, and a pre-service elementary school teacher.

\subsection{PROTOCOL}

A semi-structured interview protocol (Flick, 1998) was designed with scenarios and open-ended questions that give students the opportunity to describe in their own words what statistics terms mean so that the researcher can ascertain whether or how any lack of understanding of the term can be attributed to statistical conceptual knowledge or to English issues (e.g., does it depend on whether the Spanish word is a similar cognate or has similar usage?). The initial questions (and translations, when requested) were presented in the same manner to each student, but follow-up questions were individualized. Participants were encouraged to share their thinking as much as possible, but were not given confirmation of what answers were "correct."

The initial interview lasted about 40 minutes and consisted of a series of groups of questions. First, the participant gave some background information, especially a selfrating on their language proficiency, using the validated scales mentioned in the previous section. Then the participant was given a shuffled deck of nine word cards to go through in the order of her choice. She was asked to try to use each word in a sentence, explain the meaning of the word in her own words as she has used it, and classify this usage as "everyday" or "mathematical/statistical." The participant was then asked if she could also use that word with the other type of usage. At all points, participants were reminded that it was okay if they were not able to come up with an answer. The words selected for this purpose all had meanings in an everyday sense as well as in a mathematical and/or statistical sense. The words were bias, random, causal, correlation, significant, parameter, nominal, range, and independent. In the next part, students were given the dataset $\{1,2,3$, $4,6,6,13\}$ from Lesser (in press) and asked to provide (with reasoning) the mode, median, mean, range (note that all these numerical values differ), and how many values are "at least 6" or "at most 6." Next, participants were given the chance to discuss a prior experience where their dominant language not being the language of instruction made a difference in understanding a particular mathematics word or concept.

The remaining questions were intended to assess how language might interact with understanding the concept of independence. Participants were asked which out of five given $2 \times 2$ tables reflected situations where gender appeared to be a factor in whether or not a person was accepted for a job he or she applied for. Participants were then given pairs of events involving coin flipping and asked whether or not the events were independent and why.

The interviewing was conducted primarily by the second author (denoted by "M" in interview excerpts), who is not only fluent in Spanish and English, but who also was equipped with a Spanish translation of the interview protocol so that he could provide translation of any item on request to the interviewee. This not only helped facilitate more meaningful communication but also helped to set the interviewees at ease during the interviews, knowing that whenever they struggled, they were free to request a translation of the question into Spanish or even give part or all of their answer in Spanish. One possible indicator of their ease was the occasional use of "code-switching" (e.g., Moschkovich, 2002) into Spanish during their replies. Having the respondents attempt to answer first in English before being provided the Spanish, however, was a way to gain 
insight into what aspects of the difficulty might be classified as related to content knowledge and what aspects related to language. For further support, participants were given access to a calculator, though numbers were chosen to be small enough so that use of a calculator was not necessary.

\subsection{ANALYSIS/RIGOR}

To ensure the validity of the Spanish translation of the interview questions, the Spanish version was given to a different bilingual person with background in mathematics/statistics who independently translated the protocol back into English. This translation method (known in the research literature under varying names: "reverse translation," "back translation,” or "double translation”) yielded no major inconsistencies in either explicit denotative meaning or in conceptual or cultural connotative meaning, thus validating the appropriateness of the original translation (Marín \& Marín, 1991). In particular, the differences were all minor, such as the appearance of common synonyms or a swapped order of phrases in the sentence. For example, the protocol gave participants a set of numbers and then asked "What would you say is the mode? How did you come up with your answer?” The independent translation from Spanish back to English yielded "What is the mode? How did you obtain this result?"

To enable students to feel free to respond honestly with minimal awkwardness or conflict of interest, neither researcher interviewed either interviewee during the same semester that interviewee was learning statistics in that researcher's class. The initial interviews were conducted in October 2007 in a faculty office and were videotaped and audiotaped. The tapes were then transcribed by a colleague with one year of experience working as a professional transcriber for a major national transcription company. Interviews were also checked by a researcher fluent in Spanish to ensure accurate handling of the instances that used Spanish. As a secondary source of data, field notes were also taken during each interview, but were not as complete or rich a source of data as the tape transcripts. After independently coding the transcripts for descriptive, interpretative, and pattern codes, each researcher created a cross-case display (Miles \& Huberman, 1994). Categories identified from the displays were aggregated by researchers' consensus into the two main findings in Section 5.

Also, all 11 graduate students in one author's mathematics education research course were given (blinded) copies of the transcript and independently did coding within three given domains: culture, language, and academic content. The coding was mostly interpretative (Miles \& Huberman, 1994). While getting hands-on experience with coding analysis, the graduate student researchers also served as a robust source of triangulation, which culminated in an oral peer debriefing session as well. The goal of this stage of the analysis was to identify preliminary themes and patterns and to identify useful follow-up questions to ask the respondents in spring 2008 follow-up interviews to explore conjectures or clarify ambiguous responses. Because the graduate students were novice researchers, this use of their efforts was not intended to generate formal inter-coder agreement statistics, but rather to provide further assurance that any patterns or curiosities in the data that might have been overlooked by the researchers would be noticed by at least someone; and some of their insights indeed informed the analyses and are included in Section 5. The graduate students turned in hardcopies of the coding they had each independently done and a class period was devoted to synthesizing their results into a composite cross-case analysis that helped fine-tune the researchers' analysis.

S1 and S2 each accepted an invitation for a second interview (in April 2008, during the subsequent semester), during which member checking was conducted to ascertain 
what participants meant in a couple of key places in the transcripts. Their responses often generated follow-up questions. Still further member checking occurred in March 2009.

\section{FINDINGS}

\subsection{MOVEMENT AMONG REGISTERS}

The description of this study's first main finding will include movement or confusion among two or more of the six registers: everyday (corresponding to BICS), mathematics, and statistics registers within English (corresponding to CALP) and everyday, mathematics and statistics registers within Spanish.

Confusion between BICS and CALP registers Some instances of confusion seemed to be classifiable as involving the statistical and the everyday uses of the word, rather than going between English and Spanish, as seen here with the word range.

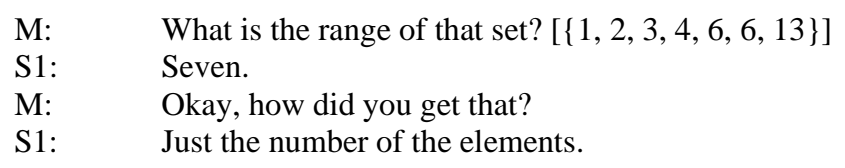

This particular misconception happened again with S1 on her follow-up interview. Here is how S2 experienced it on her initial interview.

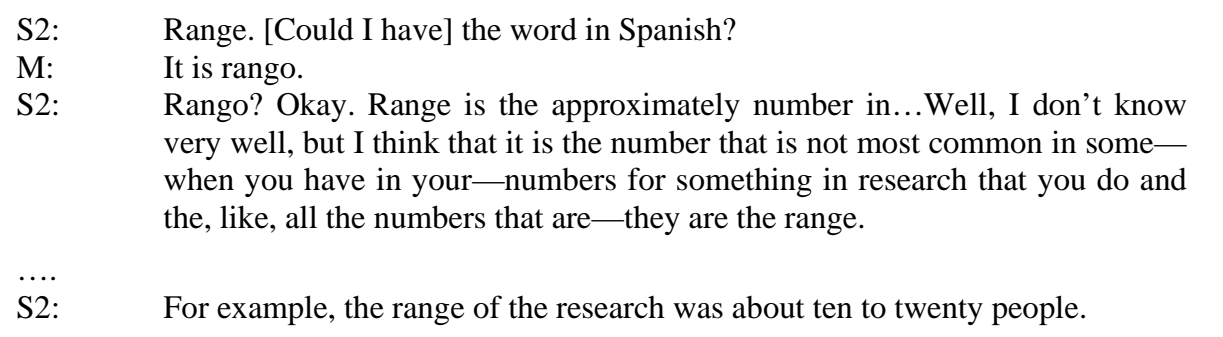

It is striking that S1 and S2 independently gave answers that suggested interference with the use of everyday English. It seems clear the interference was not with everyday Spanish because the translation of "prices range from \$10 to \$20" into Spanish and back would return as "the prices are between $\$ 10$ and $\$ 20$." Nor was the problem likely to be mathematical Spanish, because range and rango are cognates. With S1, the confusion may have been that the everyday usage of range suggests "ranging through" the "full range of" elements of the dataset, which could evoke sample size. S2 referred to "all the numbers" and then gave the endpoints of an interval. It also seems possible (but not likely) that S2's use of "all the numbers" might reflect interaction with the mathematics register, in which range is generally a set of numbers rather than a single number.

Another example of confusion by S1 and S2 between the everyday and technical register involved the term independent. Because the everyday meaning of independent can be associated with separateness (e.g., independent nations), we conjecture that this leads students (incorrectly) to equate independence with disjoint (i.e., mutually exclusive) events. (In fact, disjoint nonempty events can never be independent.) This misconception is not limited to ELLs or novice learners, but has even shown up in scholarly contexts. For example, a figure displaying non-overlapping circles in Mishra and Koehler (2006) is preceded immediately by this sentence: "We can represent this bifurcated way of looking 
at teacher knowledge as two circles independent of each other" (p. 1020). And Weisstein (2009) states that "Disjoint sets are also said to be mutually exclusive or independent."

When S2 was asked (in English, then Spanish) what she thought it means for two events to be independent, she answered, "Um, that they are - they are different, so they have no connection. They are one -they-they are separate.” Interestingly, S1 and S2 had been asked earlier in the initial interview to use the word independent in an everyday context. S1 answered that she "can be a very independent person," which she explained meant that her choices don't depend on what other people think. This answer is actually very aligned with the statistics definition of independence - that the probability of one event does not depend on the outcome of the other event. S2's example of everyday usage was "México is an independent country," which suggests a similar kind of autonomy amidst other entities. However, the researchers did not get clear usable results from attempts to see whether independence was interpreted as "separate" when asking interviewees whether various pairs of events were independent events. This was because the researchers neglected to verify that the interviewee understood wording that involved, for example, two different events associated with a single coin flip. (This is a lesson learned for future work.)

Our finding that students particularly struggle when words can be used in either academic or everyday contexts is supported by Hale (2007), who found that students (ELLs or not) "had the most difficulty when mathematical terms were words commonly used in the English language" (p. 43) and that they would believe an incorrect conclusion based on everyday language even when it differed from their conclusion based on mathematical knowledge.

A more subtle difficulty involving BICS and CALP happened when S2 was asked how many values in the dataset $\{1,2,3,4,6,6,13\}$ are at least six.

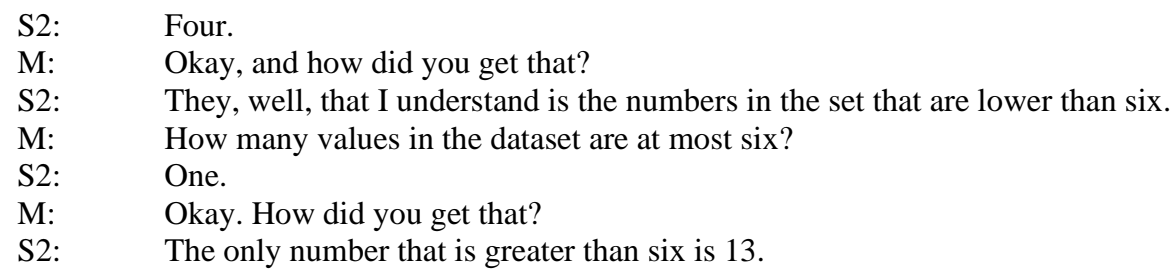

If a student does not recognize the phrases "at least six" and "at most six" in the academic context of inequalities, a natural response may be to focus just on the word "least" or "most," which in this case resulted in interpreting the question as "less than six" and "more than six," respectively. (This suggests a limitation of the student strategy of focusing on "key words.") Issues with "at least" or "at most" have implications for statistics questions involving probability and sample space. In particular, S2 was asked during a follow-up interview how many heads are possible if a coin is flipped twice. She correctly said 0,1 , or 2 , but when she was then asked what the event "at least one head" would include, she chose only " 1 " rather than " 1 or 2 ." Although this was not consistent with the kind of error she had made before, it was another example of her inability to interpret the phrase "at least." The students' struggle with this is not surprising, in light of the finding of the survey research of Nolan (2002), in which no more than $12 \%$ of university students correctly answered questions involving "at least" or "at most," but performed significantly better with all other terms. Nolan's findings suggest that there is confusion between BICS and CALP for native English speakers as well. 
Deficiencies in CALP It is insightful to note the instances where interviewees were unable to answer a question until a Spanish translation was provided, as in this excerpt from the beginning of the initial interview.

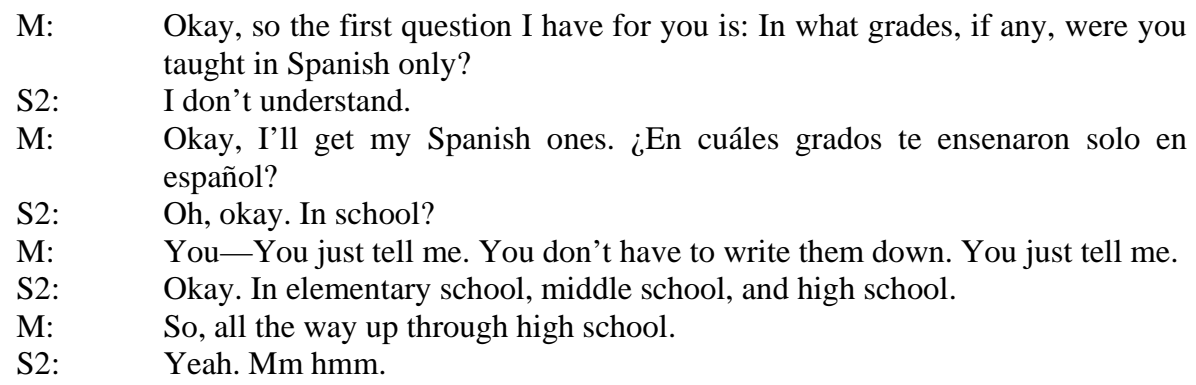

It is interesting to note that the initial question has a somewhat indirect syntax that is more commonly encountered in a formal academic setting. It seems that S2 was not used to hearing questions phrased this way as each individual word was fairly common, but she still asked for the question in Spanish. This may indicate that her CALP still may not be well developed and that she "can best understand speech that is in the present tense and uses an active voice, similar to much of their corridor conversations" (Johnson, 2010, p. 31). Or it may reflect, as a graduate student peer debriefer conjectured, saying "grades" instead of "years in school."

If the academic content register in their first language is not developed, giving a student the term in their native language will not help them do the problem in English. In this excerpt, the Spanish term clearly does not help.

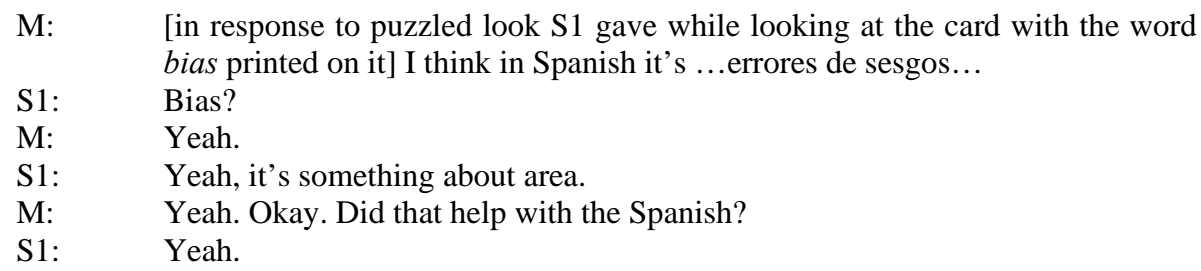

It is interesting to explore why S1 would connect bias with the seemingly unrelated idea of area. The word "sesgos" can also mean slant in English and because "slant" could refer to someone's predilection (inclinación) or a geometric object (e.g., the "slant height" of a pyramid), it seems possible that S1 assumed the term was from geometry, but she could not provide further insight or confirmation during a later member check. Neither S1 nor S2 could readily define bias, even when provided the Spanish translation "errores de sesgos," because they did not recognize the word "sesgos" either. Because the word "bias" was unfamiliar in a BICS sense, it is not surprising that it was not recognized in a CALP sense, much less recognized to have two different meanings that occur within the class textbook: (1) Prejudice or favoritism that an individual or organization might have about a particular group or ideology that might yield a "biased survey question" (Utts, 2005, p. 38) or (2) a matter-of-fact description of how much a measurement or estimate is likely to be systematically "off the mark" in a particular direction (ibid, p. 49). It is interesting that even an author (Barrett, 2007) writing for professional statisticians felt that context was insufficient to preclude the need to make such a clarification: "The term 'bias' here refers only to a measure of randomness, and does not imply intent” (p. 298).

In this excerpt, S2 does not recognize mode in English and asks for it in Spanish. 


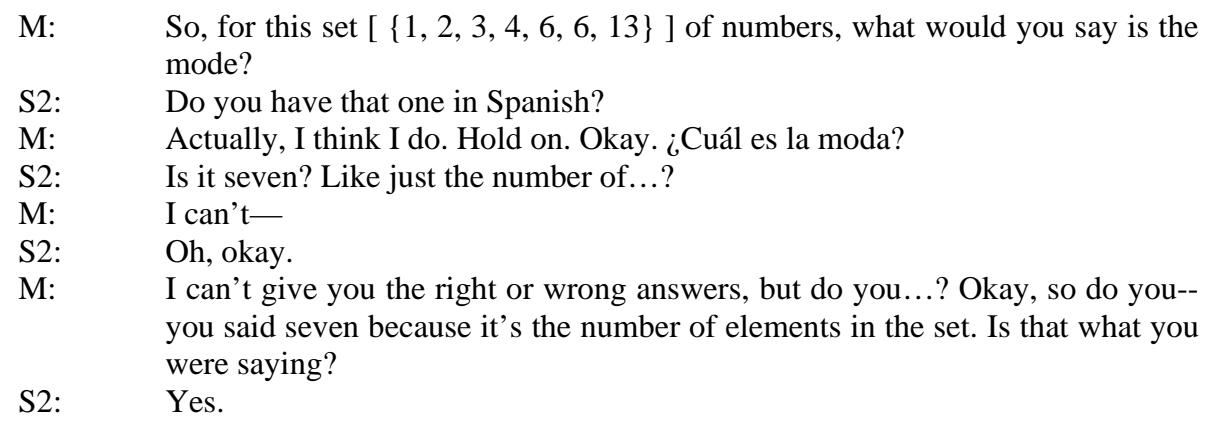

Notice that the student does not answer the question correctly even when she is given the term in Spanish. It may be the case that S1 did not fully understand the basic concepts when she learned them in Spanish and that in turn has led her to a partial knowledge of basic statistical measures when asked to complete a problem in English. A final example of exploring whether the Spanish term helps involves the median.
M: $\quad$ Okay. Okay, what is the median of [the set of numbers $\{1,2,3,4,6,6,13\}$ ].
S1: $\quad$ Do you have that one in Spanish?
M: $\quad$ Oh, that's okay. In Spanish the word is mediana. It's la mediana.
S1: If I remember, like the... I don't know if it's in the median where you add opposites and then divide it by two or where you just go to half of the...[S1 does some operations using the available calculator] Okay. It would be five.

Though S1 considered many possible strategies (e.g., the midrange), her final answer equals the mean, so the authors first conjectured that S1 may have swapped mean and median because the Spanish word for mean sounds more like the English word median than like mean (see Table 1). However, during a follow-up interview, S1 said that she obtained 5 by adding the two middle numbers in the set, then dividing by two. This is the correct process for finding the median when the sample size is even, but this data set had an odd number of values. In any case, her difficulty with this problem in English is not surprising given that she also had difficulty selecting a correct approach in her first language, and a terms handbook (e.g., COMAP, 2008) would make little difference in such situations. On a positive note, Goldenberg (2008) notes that if students learn something in their native language, then they will already know it, or can more easily learn it, in their second language. S1 noted in a subsequent member check that it was challenging when she was presented in the same day's lesson with three measures of location so similar (in both languages) to each other and to words from everyday usage (see Table 1).

A more subtle example involved the word parameter. Although parameter (like range) has a cognate word, an additional factor is that both English and Spanish words for parameter are similar to a mathematical word with a different meaning, and also correspond to a word with a potentially confusing everyday meaning. When provided with its Spanish equivalent (parámetro), S2 associated the word with linear measurement.

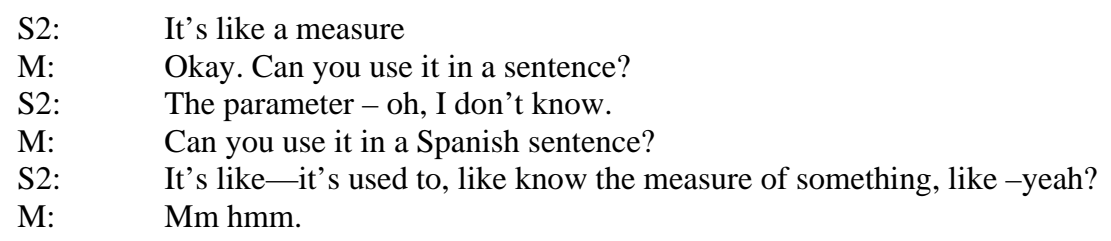




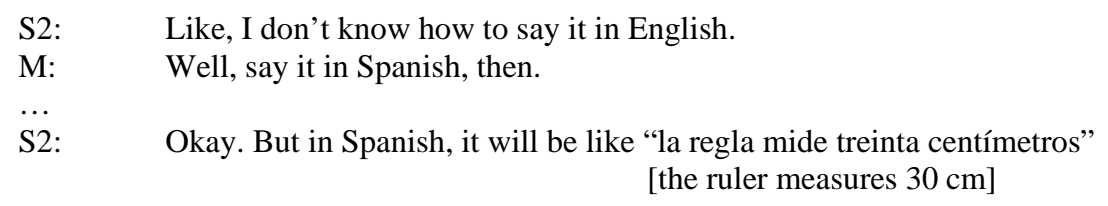

Table 1. Measures of location and similar words in English and Spanish

\begin{tabular}{ll} 
ENGLISH & SPANISH \\
\hline mode & moda \\
median & mediana \\
mean & promedio \\
average & media \\
on average & por término medio \\
average (ordinary) & mediano \\
medium (i.e., size) & medio \\
the middle one & el de en medio
\end{tabular}

One possible explanation is that this confusion arises because the Greek suffix meter means measurement, and even more importantly, because parámetro is similar (in both spelling and in syllabic stress pattern) to perímetro (the Spanish word for perimeter), and perimeter involves linear measurement. Another possible explanation is that the student may have tried to break the Spanish word parámetro into para and metro. "Metro" is a meter or an instrument for measuring, and the word "para" means for or used for. So this may explain why she mentioned something used "for measuring." A relevant secondary nuance here is that in everyday English, parameters refer to the constraints or boundaries of a situation, which more readily suggests a perimeter than it does a numerical summary of a population. The word parameter was occasionally used orally in the statistics course, but does not appear in the textbook (Utts, 2005), and so provided a useful opportunity to see how an ELL handles a term for which she has minimal familiarity.

This instance of S2 initiating communication in Spanish is unsurprising not only because of the comfort level she felt with the bilingual interviewer, but also because she first learned about measurement during the years when she was being taught in Spanish only. There is evidence (e.g., Moschkovich, 2000, 2007) that students often prefer to carry out procedures in the language in which they learned those procedures, and therefore statistics instructors may need to be prepared that a student may go back and forth between languages even within a single statistics exercise, perhaps doing the overall statistics in English, but doing the arithmetic in Spanish, and the algebra in a mixture of the two. During the authors' courses, students are often observed during group work or even during lectures asking each other questions that include use of both English and Spanish, a phenomenon about which Moschkovich (2007) cautions:

Because bilinguals use two languages depending on the interlocutor, domain, topic, role and function, researchers in bilingualism caution us against using someone's code switching to reach conclusions about their language proficiency, ability to recall a word, or knowledge of a particular technical word. (p. 132)

\subsection{THE ROLE OF CONTEXT}

Context, the second main finding, seemed to reveal a tension in that an ELL may struggle to learn if there is no context given and yet there is also a risk of an obstacle if an instructor offers a context the ELL finds unfamiliar. Context refers to the setting in which 
information is communicated and may include content, people, or environment. S2 seemed to invoke context when asked when language was an obstacle

M: $\quad$ Tell me about a time in mathematics class where your dominant language not being the language of instruction made a difference, positive or negative, in understanding a particular mathematics word or concept.

S2: Well, in-in the statistics class when the teacher is talking about the standard deviation, I-I think it's positive, because I think that in Spanish it is [speaking in Spanish, but first word is inaudible] estandard. But some-some words that the teacher says I don't understand very well.

M: $\quad$ Okay.

S2: $\quad$ And I think that also is the negative.

M: $\quad$ Oh.

S2: $\quad$ Because, I understand the concept, but I don't understand some-sometimes the words that they use- - that he use to explain.

M: $\quad$ Oh, so you-have you seen the concept before in your other classes, like when you were in high school?

S2: $\quad$ Yeah. Mm hmm.

M: Okay, and then-but, when he's explaining, because of the words that he uses...

S2: $\quad$ Mm hmm.

M: $\quad$...it confuses you.

S2: $\quad$ Yeah.

Note that S2 tries to remember learning about standard deviation in Spanish. It seems that at first, S2 recognized the term "standard deviation" and so there seems to be a tentative connection between S2's CALP in Spanish and her CALP in English. Unfortunately, the choice of different words or examples in the professor's lecture made S2 doubt her grasp of the concept of standard deviation in English CALP. This reflects a weak connection between S2's CALP in English and CALP in Spanish. As one graduate student peer debriefer noted, another factor may be that S2 understood the words "standard" and "deviation" separately from a nontechnical register, but did not know how they combined to yield a specific concept in an academic register, and this idea is discussed further in Section 5.3.

The following excerpt (where $\mathrm{M}$ is asking S2 if given events are independent) gives another example of S2's difficulty with a question's context.

M: Okay. Part B: The first event is "dime lands on heads.” The second event is "quarter lands on tails."

S2: What is "tails" on the quarter?

M: $\quad$ Quiere decir.. a ver [it means... let me see] Give me a second. La moneda cae con cruz hacia arriba o cruz hacia abajo o no con cara... cara y cruz [the coin falls with the cross up or the cross down, oh no with the face... face and cross (i.e., heads and tails)]

S2: $\quad$ Okay.

M: $\quad$ So, cara is heads, cruz is tails.

S2: $\quad$ Um, I think that they are independent.

It is interesting to note that even the simple setting of a coin landing on heads or tails may confuse. This confusion may also be cultural as many coins in Latin America do not have "tails" on the back of the coin. A graduate student peer debriefer noted that Mexican coins' sides are sello (seal) and águila (eagle). 
Because S1 had taken statistics over a year ago and was now taking required mathematics courses, her mathematics register was more active or primed than her statistics register. Thus, many of her responses to the word cards used a mathematics context, not a statistics one, even though the consent form for the interview mentioned statistics not mathematics. One example was the word card "independent," for which S1 mentioned "independent variables" and then elaborated in terms of the variables one would plot on the horizontal axis of a graph (i.e., she was not meaning independent random variables in statistics!). Another example was that for the word card "range," S1 could give an example only for mathematics ("like the range of the function is from the reals_-all reals"), but not for statistics.

During the follow-up interview, when S2 was shown her last in-class statistics exam and asked which words caused any confusion, she named three: bracket [as in income bracket], scatterplot, and ski. Note that only one of the three words is a statistics term, which is consistent with interview statements by S1 and S2 that in lectures and tests it was usually the everyday English words, not the statistics words, that caused difficulties, and that access to a bilingual handbook of statistics terms (e.g., Dragt, 2009) would not make a large difference.

The word "ski" was in a question taken almost verbatim from a conceptual exercise in the course textbook (Utts, 2005, pp. 214-215). At the time, the instructor did not question using this problem because it was based closely on a problem previously assigned for homework. However, it is clear in retrospect that the context of a ski resort was not one that students living in a high-poverty, desert community could reasonably be assumed to relate to well enough to do the context-embedded task of interpreting a real-life correlation. A similar point is made by Siegel, Wissehr, and Halverson (2008):

...a student's personal background and experience is important in how he or she interprets science assessments (Solano-Flores \& Nelson-Barber, 2001)... an underprivileged student who has never left New York City may...be at a disadvantage when completing a question that uses a golf course as the context for a physics problem. (p. 45)

Such cultural awareness, however, might not be something students have the perspective or assertiveness to seek. When S1 was asked in a follow-up interview what is important for teachers to know about language or culture to teach students from this region, she responded that culture was not really a major factor. That said, the first author received an appreciative response in the class meeting when he shared the example of toma todo (McCoy, Buckner, \& Munley, 2007), a Mexican game of chance involving a six-sided top called a pirinola.

\subsection{DISCUSSION OF FINDINGS}

Summary The first main theme that emerged from coding the transcripts was movement among registers. The examples of Section 5.1 suggest that there are instances where a student, even one who has already been exposed to the academic meaning of a term (such as range or independent), may be more influenced by the use of the term in the everyday register. In such instances, offering the student a translated word will generally make little difference. Sometimes the problem is that students may understand the words individually, but not as they are grouped in an intact phrase (e.g., "at least six" or "standard deviation"), which reveals a limitation of the "key words" strategy. Examples of common intact phrases in statistics include box-and-whisker plot, stem-and-leaf plot, expected value, line of best fit, degrees of freedom, sum of squares, regression to the mean, coefficient of determination, and the idiomatic "in the long run." Johnson (2010) 
notes that the full phrase won't usually be in a general dictionary and word-by-word translation attempts may not yield a coherent result.

These results can be interpreted as consistent with the perspectives and limitations Moschkovich (2002) has articulated about viewing ELLs as acquiring vocabulary and mapping meanings among registers. She insists that while "differences between the everyday and mathematical registers may sometimes present obstacles..., everyday meanings and metaphors can also be resources” (p. 196). The authors' data has only a few instances of students demonstrating such resources (e.g., using analogies of self or country in describing the meaning of independence) because the protocol was largely a series of short items, but Martin (2003) provides a rich collection of statistics analogies that can be resources.

It was also observed that deficiencies in CALP in the native language could hinder students' understanding of statistics. From vignettes such as how S1 handled the word "bias" and how S2 handled "mode," it seems that these deficiencies in CALP in the native language make tools such as a Spanish-English list of statistics terms ineffective because the content knowledge is not available in the student's native language. Moreover, it also seems to indicate that students whose CALP is strong in their first language will have an easier time learning the content in their second language (Cummins, 1992).

It is conjectured that statistics will play out differently than mathematics when it comes to movement among registers simply because a certain amount of mathematics is normally encountered or required before one studies statistics. (That said, this may become somewhat less of an issue as more statistics makes its way down into the K-12 curriculum.) Thus, an ELL would likely have a statistics register that was less (perhaps much less) developed than a mathematics register in their home language and this would affect the pathway needed to make connections with their statistics knowledge.

The second main theme that emerged from transcript coding was the roles of context. The context of the teacher's presentation style kept S1 and S2 from readily grasping the concepts of expected value and standard deviation, respectively. Also, some test questions' context (e.g., ski resort) was problematic and the context of the sides of United States coins was sufficiently unfamiliar as to interfere with S2 addressing a question about independence.

As an aside, there may be overlap or interaction between these two themes. For example, one might argue that the instances of S1 more readily giving a mathematics usage instead of a statistics usage (for words such as range and independent) could be viewed either as context (she was talking to the person who had taught her in a mathematics course, which she had taken more recently than the statistics course) or as register confusion (between the statistics register and mathematics register).

By exploring specific examples within each theme, a better (though not complete) understanding has formed regarding potential pitfalls and obstacles for ELLs in learning statistics. Because both ELLs and non-ELLs must develop and navigate among mathematics and statistics registers, it appears that the register confusion may likely play out in a similar manner for both groups, with the ELLs experiencing a slightly higher incidence of both obstacles and resources. The role of context, however, seems much more likely to play out in a more distinctive way for ELLs, though further research would be required to explore this conjecture fully.

The role of context also seems to play itself out in a more distinctive way for ELLs learning statistics than for ELLs learning mathematics because statistics inherently involves and requires more context than does mathematics (as mentioned in Section 1) and this extra context provides cues that help the ELL in making connections to the content. Possible supporting evidence of this is how much more sustained the use of 
analogies can be in statistics teaching (compared to mathematics teaching), such as the courtroom analogy for hypothesis testing (Martin, 2003). That said, it should be noted that this particular analogy may play out differently for ELLs from countries with a Napoleonic Code of Law (that presumes guilt until proven innocent) which contrasts from the typical textbook presentation of innocence as the null hypothesis. This is another way in which statistics is more dependent than mathematics is on context and culture.

As was hoped, further reflections on the examples associated with the emergent themes have informed the recommendations for future research as well as for teaching, and we elaborate in Sections 6 and 7 respectively.

Limitations This research is only an initial attempt to identify and explore specific aspects of how Spanish-speaking ELLs experience learning statistics. While the researchers accepted all eligible participants who volunteered, and while case studies have certainly been done on as few as two participants, it is nevertheless a limitation that the authors were not able to recruit more participants within the time and resource constraints. Also, this study did not (nor did it intend to) do a side-by-side comparison of ELLs with non-ELLs. It is a delimitation that this study included only Spanish-speaking ELLs, which comprise $80 \%$ of the ELLs in the US (and higher in the author's geographic region). Whereas Khisty (1997) notes that the concepts and applications of teaching ELLs "apply equally well to any group of students whose home language is other than English" (p. 93), Moschkovich (2007) implies that not all languages may have equally developed registers in academic statistics (p. 133).

It seems a less crucial limitation that participants self-rated their language proficiency rather than having a third-party language expert assess it. Their ratings, however, certainly seemed to the researchers to be consistent with their communication during the interviews.

Also, there were instances where it was not always possible to determine definitively whether a gap was due to incomplete grasp of (academic) language or due to incomplete understanding of the (statistical) content, as it has been suggested that a deficiency of the latter can lead to poor use of language (Meaney, 2002). Moschkovich (2002) reminds us that the origin of an error is not as crucial as uncovering what students are able to communicate, depending on one's goals. In any case, Kotsopoulos (2007) notes that student language will become more precise as students continue to work and communicate, perhaps not unlike the progression of language towards normative understanding suggested by the four successively more precise explanations of $\mathrm{p}$-value in Vogt (2007, p. 13).

It is possible that it would have been more helpful, as a graduate student peer debriefer suggested, for each interviewee to read and respond in writing to the questions in a private, untimed environment before being interviewed. It also would have been helpful to vet certain questions further (e.g., those on independent events) whose wording was sufficiently convoluted or ambiguous so that the resulting responses were not as meaningful or informative as they might have been.

Although there were multiple types of triangulation (e.g., having more than one participant, more than one researcher, peer debriefing and member checking), it is a limitation that data and observations involving the participants were limited primarily to the field notes and taped interactions from an interview setting (with the exception of a few artifacts such as student course exams) and therefore focused only on students interacting individually with statistics content. Moschkovich (2002) would claim that the manner in which ELLs learn statistics is ultimately more than just learning vocabulary or being able to negotiate among registers, but is a situated sociocultural activity in which 
students learning statistics participate in communities with various norms (e.g., "status equalization" as described in Khisty, 1997) and resources (e.g., everyday meanings and analogies such as in Martin, 2003). Whereas there certainly would be much to learn from observing students communicate about statistics in explicitly social or cultural contexts, the perspective articulated by Moschkovich (2002) assumes that any learning is inherently social and cultural.

\section{DIRECTIONS FOR FUTURE RESEARCH}

\subsection{MODELING THE LEARNING PROCESS}

This research is an initial attempt to identify and assess specific aspects of how Spanish-speaking ELLs experience learning statistics and further study is planned on a broader set of vocabulary and concepts with a broader variety of contexts that acknowledge how this subpopulation is diverse in "length of residence in the US, language proficiency in English, language proficiency in Spanish, prior school experience, and socioeconomic status” (Moschkovich, 2003, p. 5).

Based on the difficulty S2 had with the question "In what grades, if any, were you taught in Spanish only?" in Section 5.1, it would be interesting to investigate empirically the possible benefit of using more streamlined language that minimizes clauses and parenthetical remarks. Consider the textbook description the first author wrote for finding the first quartile (COMAP, 2009, p. 161): "Use the median to split the ordered data set into two halves - an upper half and a lower half. The first quartile is the median of the lower half." The textbook's previous edition said "Arrange the observations in increasing order and locate the median $\mathrm{M}$ in the ordered list of observations. The first quartile is the median of the observations whose position in the ordered list is to the left of the location of the overall median.” It would be interesting to investigate empirically the conjecture that students (especially ELLs) will prefer such revised wording because it better resembles direct language patterns of BICS.

Also, it would be fascinating to map formally the trajectory of how students move among and between registers in BICS and CALP in English and in Spanish during episodes of individual or group learning. During a follow-up interview, S1 was shown Pilar (2003, Figure 4.2) and commented that such a model was a very useful vehicle to describe her movements among registers. That figure represents strength of and movement among the realms of everyday and specialized language for the dominant and weaker languages. As part of a future study, this model could be adapted and fine-tuned for statistics and applied to empirical narrative data. In particular, the model suggests there may effectively be an intermediate stage between BICS and CALP which uses "mathematized-situation language" that is more focused than "everyday language" but is not yet using the precise academic technical terms. The model in Moschkovich (2000, Figure 9.3) shows double-headed arrows for all six possible connections among four registers (Spanish mathematics, everyday Spanish, English mathematics, and everyday English). Modifying this for statistics might involve including the two additional registers of Spanish statistics and English statistics in a way that indicates that their development usually occurs after the respective mathematics registers are already in place, considering the mathematics courses that generally occur or are required before taking a first full course in statistics.

The research of Mestre, Gerace, and Lochhead (1982) found that language differences sometimes caused Spanish-speaking ELLs to mistranslate mathematics word problems into equations, so it is not unreasonable to ask whether there may be specific features of 
Spanish that play out in a distinctive way when learning statistics. For example, Spanish has a "double negative" that has the meaning of a single negative in English, so there may be an initial possibility of confusion when Spanish-speaking ELLs encounter the double negatives in English that permeate the language of hypothesis testing, such as "we fail to reject the null hypothesis." The phrase "fail to reject the null hypothesis of no difference" may be perceived as a triple negative. The use of double (or more) negatives, however, is not common in everyday conversational English and is something students may struggle to get used to in the academic context of a statistics class. Adapting a pitfall of negation identified by Mestre (1988), it would be interesting to see whether the ANOVA alternative hypothesis "not all means are equal" gets interpreted as "some means are equal" or "some means are not equal."

Considering the preceding examples, this is an important place to warn of the pitfall of focusing unduly on disadvantages, as this can lead to "deficit models." Khisty (1997) discusses the importance of learning activities that "incorporate students' language, culture, and community rather than reflect beliefs that these characteristics are limitations.” A reading of Moll (1992) suggests that the emphasis on community in the cultures of many ELLs might be parlayed into a resource-rich classroom learning community in which real-life contexts for (statistics) applications can naturally and readily emerge. While articulating her situated-sociocultural perspective, Moschkovich (2002) identifies numerous resources ELLs use to communicate, including "gestures, objects, everyday experiences, their first language, code switching and mathematical representations” (p. 207). One example consistent with her perspective could be an ELL who, when asked to describe when the mean could exceed the median, is not able to state a phrase such as "a unimodal, right-skewed distribution," but yet communicates the essential idea with informal language or by drawing or tracing the shape.

It is also worthwhile to identify ways in which features of an ELL's language can help reinforce concepts of statistics. For example, Bannon (2007) notes that in Malay, the expression for the mean is sama rata, which translates roughly as "same level." Thus, the language invokes the "leveling" conceptual interpretation of the mean. This interpretation is also reflected in the Arabic origin of the word "average" (Konold \& Pollatsek, 2002). Similar examples might be identified in Spanish, at least through cognates. For example, the word nominal [as in nominal data] is from a Latin word related to "name," and the Spanish words for nominal and name are nominal and nombre, respectively. Also, because ELLs are used to having to go back and forth between English and Spanish, they may be more primed than monolinguals to navigate among various academic registers. This idea of one's first language being a resource more than an obstacle is supported by Rollnick (1998) and by Valverde (1984), who reports the following:

A consistent finding is that bilingual students do better in mathematics when taught bilingually than monolingual English-speaking Hispanic students or students with a

limited proficiency in English do when taught monolingually. This finding even extends to the college-age student. (p. 129)

Moschkovich (2007) adds that bilinguals may have the advantage of selective attention - an enhanced ability to choose which pieces of information or aspects of context to emphasize.

\subsection{INTERVENTIONS}

With increased understanding of ELLs' challenges in statistics, it will be useful to analyze the similarities and differences between effective interventions for ELLs and effective interventions for native English speakers. This will be important in light of 
recommendations such as the National Council of Teachers of Mathematics' position statement ([NCTM], 2008) on teaching mathematics to ELLs, which states that teachers "should engage ELL students explicitly in the use of this [academic] language, integrating language objectives with goals for content understanding." In other words, how can language objectives be integrated without unduly cutting into instructional time, in a way that takes into account the needs of ELL and non-ELL students? Flores (1997) asserts that recommendations for how ELLs "can best learn mathematics and how they should be taught do not differ significantly from what is best for other groups" (p. 90). If his claim for the context of mathematics education is also valid in statistics education, then it should be possible for statistics instructors to meet the needs of ELL and non-ELL students. What is unique about teaching ELLs may ultimately be not the techniques but the goals of use. Khisty (1997) gives the example that concrete manipulatives help everyone's conceptual understanding, but for ELLs they also help support "what a student hears and subsequently understands” (p. 97).

A particular intervention that would be interesting to explore is whether it is better to define terms formally before explaining a concept (as mathematicians typically do) or, as some studies on language acquisition suggest, informally exploring concepts and then providing students formal language for the concepts being studied (Garrison \& Mora, 2003; Murrey, 2008). Starting with everyday language reflects how CALP development lags BICS. This may also parallel the innovation used by Utts (2005) in introducing algebraic notation (summation signs, Greek letters, etc.) at the end of each chapter so that the student first encounters the content more informally - conceptually, graphically, numerically, and verbally. There may also be connections to recent experimental research in science education (Brown \& Ryoo, 2008) that found minority (mostly Hispanic/Latino) fifth-graders taught concepts with everyday language before introducing scientific language demonstrated (on a written post-test) a larger gain in conceptual understanding (as compared to the control group, who were taught without delaying the introduction of scientific terms), whether test questions were written in everyday or in scientific language. A related dynamic discussed by Brown and Ryoo (2008) is that by making students explicitly aware of the components of, and transitions between content and language instruction, students were more able to form a scientific identity that did not conflict with their cultural identity. ELL issues in science education are further situated by Lee and Luykx (2006).

A more long-term direction for research in the arena of ELLs learning statistics would be to apply the situated-sociocultural approach of Moschkovich (2002) in mathematics education to statistics education. It would be interesting to observe groups of ELLs at work on statistics problems. What norms do the groups have? How is language used in learning statistics? Do they use English, Spanish, or a combination to talk about statistics problems (Moschkovich, 2007)? What linguistic and cognitive tools do ELLs bring that help them learn statistics? Is a statistics course structured to allow ELLs to interact in ways that promote learning? How is ELLs' discourse similar to and different from the type of discourse that occurs among monolingual students, or teachers, or statisticians? How do ELLs engage in statistical discourse across different "genres" (e.g., presentations of data, simulations, explanations, analyses)? How does the situated-sociocultural approach prepare pre-service teachers to address English language proficiency standards (recently mandated by several states) in each content area for ELLs at varying levels of English proficiency for all modes of communication (reading, writing, speaking, and listening)?

Moschkovich (2003) has noted that the NCTM's new emphasis on mathematical discourse will result in "increasing oral activities and decreasing activities involving 
solitary text comprehension” (p. 6). It is conjectured that this new direction could be viewed as consistent with the College GAISE guidelines adopted by the American Statistical Association (ASA, 2005), which call for strategies that incorporate context. One strategy calls for active learning in the classroom, and including among its benefits "the practice students get communicating in the statistical language and learning to work in teams." In general, however, the College and Pre-K-12 GAISE guidelines do not explicitly acknowledge ELLs, nor did Groth (2008) report such acknowledgment in discourse about GAISE implementation by precollege teachers (who are even more likely to teach ELLs than university professors are). One of the bullets under the third GAISE Goal (ASA, 2005) for the introductory course- - "Students should understand the parts of the process through which statistics works to answer questions"- is "How to communicate the results of a statistical analysis," but the language does not get specific enough to focus on the dynamics of this communication.

Another important direction for future research is to take statistics curricula, especially those with sensitivity to or emphasis on language (e.g., Sullivan, 2010), and examine them from the perspective of social semiotics (e.g., Ernest, 2008), the third-level meaning of ethnostatistics (Gephart, Jr., 1988; this uses literary and textual analysis to examine the rhetoric of statistics), or a systemic functional linguistics theory called "functional language analysis" (Fang \& Schleppegrell, 2008), which goes beyond the usual focus on vocabulary and keywords to understand "how knowledge is presented in characteristic patterns of language” (p. 3) in a given content area.

It would be interesting to explore further the ways in which ELLs and non-ELLs might learn explicitly how the very grammatical structures and patterns of statistical language reinforce the idea of statistics as "the grammar of science" (as Karl Pearson titled his 1892 book). For example, a journal article's typical use of passive voice or turning verbs into nouns may have the effect of reinforcing a view of agent-less "objectivity" about the use of statistics or even an unstated acceptance of the frequentist paradigm of inference. If such connections seem far-fetched, consider the disclosure of Berry (1996): "In keeping with a subjective nature of the Bayesian approach, I write in the first person and draw my own conclusions in the various examples" (p. iv). In any case, employing tools such as functional language analysis would clearly go beyond the first recommendation of ASA (2005) that describes "understanding the basic language of statistics" as "knowing what statistical terms and symbols mean and being able to read statistical graphs."

\section{RECOMMENDATIONS FOR TEACHING}

The following implications and recommendations are suggested by or respond to the specific findings from this study and also reflect the synthesis of literature (spanning statistics education, mathematics education, science education, and second language acquisition) that was analyzed in the course of doing this research.

\subsection{RECOMMENDATIONS RELATED TO FINDINGS ON REGISTERS}

Wait time ELLs need more time to process professors' questions (Fischer \& Perez, 2008; Gibbons, 1998). Based on the prior discussion of movement among registers, ELLs may need to hear the question in English, translate it into Spanish (where their academic prior knowledge resides), answer the question, and then translate the answer back into English. It is possible that an ELL in a traditionally-taught university lecture course will not have the time to understand and answer a question. Therefore, it is important that 
professors wait a sufficient length of time for their questions to be processed and then answered by ELLs. Gibbons (1998) states that

when teachers wait for three or more seconds, there are significant changes in student use of language and in the attitudes and expectations of both students and teachers.... the importance of wait time is increased for students who are formulating responses in a language they do not fully control. (pp. 112-113)

Emphasis on the statement or setup of a problem Section 5 revealed how easily an instructor might falsely assume that a question's vocabulary and grammatical structure are clear. Therefore, making sure students are able to determine efficiently what a question is asking and translate it into appropriate statistical terminology is critical. To this end, Mestre (1986) notes that classroom drills in solving problems from beginning to end would be less useful to ELLs than drill work in the first few steps of the problem-solving process.

Multiple terminology for one concept Often students do not answer a test question only because they don't recognize a synonymous term or phrase. Burrill (2008) gave the examples in mathematics such as "multiplicative inverse" versus "reciprocal," or "base times height" versus "length times width.” In statistics, examples could include "median" versus "second quartile" or " $50^{\text {th }}$ percentile," "line of fit" versus "least squares line" or "regression line," and "z-score" versus "standard score" or "standardized score." When assessing students, instructors should be intentional and explicit about when they are testing for recognition of alternative terminology in addition to the underlying concepts. If not, teachers could be prepared to supply equivalent phrases upon request. For example, the student who expressed unfamiliarity during the interview with the word "scatterplot" could be offered alternatives such as scatter graph, scatter diagram, scatter chart, or X-Y plot.

Vocabulary activities Winsor (2007) describes a "word squares" activity used to solidify a recently introduced term. Students write a vocabulary term in English and Spanish in the top two quadrants of a 3" $\times 5$ " note card divided into four quadrants (see Figure 1). In the bottom two quadrants, students put a definition of the statistics term in their own words and a pictorial representation of the concept in the other quadrants. Related organizers for connecting vocabulary and conceptual understanding appear in Gay (2008). As Santa Cruz (2009) cautions, ELLs should be engaged in "conversations that go beyond the translation of vocabulary to include authentic communication about mathematical concepts” (p. 4) Word squares can help to assess whether students have engaged in authentic mathematical communication because the lower left quadrant of a word square is the student's own definition. If a student is unclear on a concept, it will be apparent in the student's word square definition. Johnson (2010) offers variations on this and related strategies.

For teachers who want to offer students a resource that permits only identifying corresponding terms between languages but without actually providing a definition and illustration of the concept, there is a bilingual mathematics terms handbook available (e.g., COMAP, 2008), which is more limited in scope than a bilingual mathematics glossary (e.g., COMAP, 2004). A multilingual handbook of statistical terms published by the International Statistical Institute (Dragt, 2009) includes English, Spanish, and over 25 other languages. In light of the discussion (in Section 5.1) that a list of terms may be of limited use for students without CALP in their first language, it may be more helpful to make ELLs aware of bilingual resources that have more context than a word list. For 
example, probability and statistics applets in the National Library of Virtual Manipulatives or the Shodor Interactivate websites have Spanish counterparts available at http://nlvm.usu.edu/es/nav/ and www.eduteka.org/MI/master/interactivate/ respectively.

\begin{tabular}{|l|l|}
\hline Statistics term in English & Statistics term in Spanish \\
\hline Definition in student's own words & Example or picture of the statistics concept \\
\hline
\end{tabular}

Figure 1a. Format of a word square

\begin{tabular}{|l|l|}
\hline Mean & el promedio \\
\hline $\begin{array}{l}\text { la suma de los valores de los datos } \\
\text { dividida por el número de elementos en la } \\
\text { suma }\end{array}$ & $\begin{array}{l}\text { En el conjunto }\{1,2,3,4,20\} \text { para encontrar el } \\
\text { promedio suma todos los números y divide por } \\
5 \text { porque hay cinco elementos en el conjunto. }\end{array}$ \\
$\begin{array}{l}\text { the sum of the values in the dataset } \\
\text { divided by the number of elements in the } \\
\text { dataset }\end{array}$ & \begin{tabular}{l} 
el promedio $=(1+2+3+4+20) / 5=6$ \\
\hline
\end{tabular}
\end{tabular}

Figure 1b. Word square for the term "mean"

Group work The sociocultural approach discussed in Section 6.2 and the overall ELL literature suggest that ELLs should benefit from cooperative learning (Fischer \& Perez, 2008; Gibbons, 1998; Goldenberg, 2008). Small-group discussion of content promotes metacognition, strengthens the ELLs' CALP and conceptual knowledge (Gibbons, 1998; Winsor, 2007), and is consistent with the ASA (2005) observation that "Other benefits of active learning methods are the practice students get communicating in the statistical language and learning to work in teams." It should be noted, however, that the use of group work is not an all-purpose solution, and will have more effectiveness when used selectively for particular instructional goals. From his research with predominantly Hispanic children, DeAvila (1988) discusses how direct, whole class instruction may be perfectly adequate for tasks of low cognitive demand, whereas working and discussing in groups may be more appropriate for more conceptual tasks. Khisty (1997) and Moschkovich (2003) give further discussion and caveats on group work for Hispanic populations.

\subsection{RECOMMENDATIONS RELATED TO FINDINGS ON CONTEXT}

Contextualized instruction ELL learning needs to take place in a context that is meaningful to the student (Fischer \& Perez, 2008; Gibbons, 1998; Goldenberg, 2008; Winsor, 2007). As noted in Section 5.2, for examples such as the ski resort, participants had difficulty with understanding concepts and completing problems when they did not understand the context. Seemingly trivial acts such as providing students a picture of what the question is asking can help ELL students understand the concept and complete the problems (Fischer \& Perez, 2008). Contextualizing instruction can reinforce meaningful engagement in authentic learning activities, as recommended by Murrey (2008).

Multiple modes and representations Many suggestions for adaptations of pedagogy and assessment suggested in the context of the middle school classroom where some 
ELLs may have even weaker English backgrounds (Pappamihiel \& Mihai, 2006) may apply to classrooms of older students as well. For example, Carrier (2005) notes that the same multiple modes of input (i.e., including less language-dependent modes such as pictures, graphic organizers, demonstrations, videos, manipulatives, etc.) instructors can use to present information can also be used by ELLs to demonstrate understanding they have that would have been difficult to express orally in English, which is consistent with Moschkovich (2002), as discussed in Section 6.1. Murrey (2008) suggests that having such multiple entry points and scaffolds are helpful not only in the direct way of communication, but also in the indirect way of helping create a low-anxiety environment. Examples of multiple representations of a statistical phenomenon are given by Lesser (2001).

Multiple contexts for one word Instructors should increase awareness of words that have meaning in both everyday and statistical contexts (e.g., association, average, confidence, correlation, independent, mean, median, mode, population, random, range, significance, etc.) and highlight any connections between their BICS and CALP meanings that will help students distinguish and recall the statistical usage. Concrete examples of this can be found in some recent curricula. For example, Bock, Velleman, and DeVeaux (2007) point out to readers that "the range is a single number, not an interval of values, as you might think from its use in common speech" (p. 75). This might have helped the respondents avoid the confusion reported in Section 5.1. The first author contributed examples to COMAP (2009) that connect with everyday meaning for words such as combination, confounded, and median, and offers this for the latter word: "Just as a median divides a road into two halves (with opposite directions of travel), a median divides a [ordered] dataset into two halves!” (p. 159). This is an example where the everyday register can work as a resource rather than an obstacle.

A related further strategy (Adams, Thangata, \& King, 2005) is to present and discuss any "homophonic partners" an introduced word may have, such as complement/compliment, discrete/discreet, or mode/mowed. It can even be helpful to distinguish between words that are not true homophones, but are similar enough in sound and/or appearance to be confused with each other, such as causal/casual or (as suggested by Section 5.1) median/medium.

\section{ACKNOWLEDGEMENTS}

This work is more than the sum of the equal contributions of the authors, who express appreciation to $S E R J$ referees and editors for helpful feedback, to graduate students Orlando Pajon and Melissa Pugh for independent translation work, to Pajon for conducting a prior pilot study for a spring 2007 research class taught by the second author) that helped inform this research, to the graduate students (Heidi Arellano, Steven King, Oscar Madrid, Kyle Newman, Casey O’Dwyer, John Patrick, Pedro Reyes, Daniel Saldívar, Brenda Trumble, Guadalupe Valenzuela, and Andy Waxman) in the first author's spring 2008 research course for peer debriefing of transcript analysis, to Racheal Winsor for expert transcription of the interviews, to graduate student Tami Dashley for thoughtful proofreading, and to research linguist Kerrie Kephart for very helpful conversation and references. This work was supported in part by Project LEAP-UP (US Department of Education grant \#T195N070132). 


\section{REFERENCES}

Adams, T. L., Thangata, F., \& King, C. (2005). Weigh to go: Exploring mathematical language. Mathematics Teaching in the Middle School, 10(9), 444-448.

American Statistical Association (2005). Guidelines for assessment and instruction in statistics education: GAISE college report.

[Online: http://www.amstat.org/education/gaise/GAISECollege.htm]

Bannon, T. J. (2007). The mean means sama rata. Mathematics Teacher, 101(5), 326-327.

Barrett, B. E. (2007). Detecting bias in jury selection. American Statistician, 61(4), 296301.

Batt, E. G. (2008). Teachers' perceptions of ELL education: Potential solutions to overcome the greatest challenges. Multicultural Education, 5(3), 39-43.

Berry, D. A. (1996). Statistics: A Bayesian perspective. Belmont, CA: Duxbury.

Beyth-Marom, R., Fidler, F., \& Cumming, G. (2008). Statistical cognition: Towards evidence-based practice in statistics and statistics education. Statistics Education Research Journal, 7(2), 20-39.

[Online: http://www.stat.auckland.ac.nz/ iase/serj/SERJ7(2)_Beyth-Maron.pdf]

Bock, D. E., Velleman, P. F., \& DeVeaux, R. D. (2007). Stats: Modeling the world (2nd ed.). Upper Saddle River, NJ: Pearson.

Bourque, A., \& Jacques, S. (1995). Increasing comprehension skills through listening and asking questions. In G. Duquette (Ed.), Second language practice: Classroom strategies for developing communicative competence (pp. 14-23). Bristol, PA: Multilingual Matters Ltd.

Brown, B. A., \& Ryoo, K. (2008). Teaching science as a language: A 'content-first' approach to science teaching. Journal of Research in Science Teaching, 45(5), 529553.

Burrill, G. (2008, April). Addressing tough-to-teach and tough-to-learn. Paper presented at annual meeting of National Council of Supervisors of Mathematics, Salt Lake City, UT.

Carrier, K. A. (2005). Key issues for teaching English language learners in academic classrooms. Middle School Journal, 37(2), 4-9.

Chastain, K. (1988). Developing second-language skills. Theory and practice. New York: Harcourt Brace Jovanovich.

Chen, X., \& Li, Y. (2008). Research in brief: Language proficiency and mathematics learning. School Science and Mathematics, 108(3), 90-93.

Cobb, G. W., \& Moore, D. S. (1997). Mathematics, statistics, and teaching. The American Mathematical Monthly, 104(9), 801-823.

Collier, V. (1987). Age and rate of acquisition of second language for academic purposes. TESOL Quarterly, 21(4), 617-641.

Consortium for Mathematics and its Applications (2004). Mathematics as a second language: [English/Español] Mathematical glossary. Bedford, MA: Author.

Consortium for Mathematics and its Applications (2008). Mathematics as a second language: [English/Español] Terms handbook. Bedford, MA: Author.

Consortium for Mathematics and its Applications (2009). For all practical purposes: Mathematical literacy in today's world (8th ed.). New York: Freeman.

Cummins, J. (1979). Linguistic interdependence and the educational development of bilingual children. Review of Educational Research, 49(2), 222-251.

Cummins, J. (1992). Language proficiency, bilingualism, and academic achievement. In P. A. Richard-Amato \& M. A. Snow (Eds.), The multicultural classroom: Readings for content-area teachers (pp. 16-26). Reading, MA: Addison Wesley. 
Dale, T. C., \& Cuevas, G. J. (1992). Integrating mathematics and language learning. In P. A. Richard-Amato \& M. A. Snow (Eds.), The multicultural classroom: Readings for content-area teachers (pp. 330-348). Reading, MA: Addison Wesley.

DeAvila, E. A. (1988). Bilingualism, cognitive function, and language minority group membership. In R. R. Cocking \& J. P. Mestre (Eds.), Linguistic and cultural influences on learning mathematics (pp. 101-121). Mahwah, NJ: Lawrence Erlbaum Associates.

Dragt, J. (Ed.) (2009). ISI Multilingual Glossary of Statistical Terms. International Statistical Institute.

[Online: http://isi.cbs.nl/glossary/]

Ernest, P. (2008). Towards a semiotics of mathematical text. For the Learning of Mathematics, 28(3), 42-49.

Esch, C. E., Chang-Ross, C. M., Guha, R., Humphrey, D. C., Shields, P. M., TiffanyMorales, J. D., et al. (2005). The status of the teaching profession. Santa Cruz, CA: Center for the Future of Teaching and Learning.

Fang, Z., \& Schleppegrell, M. J. (2008). Reading in secondary content areas: A language-based pedagogy. Ann Arbor, MI: University of Michigan Press.

Fischer, J., \& Perez, R. (2008). Understanding English through mathematics: A researchbased ELL approach to teaching all students. Research Monograph of TODOS, 1, 4358.

Flick, U. (1998). An introduction to qualitative research. Thousand Oaks, CA: Sage.

Flores, A. (1997). Sí se puede, 'it can be done': Quality mathematics in more than one language. In J. Trentacosta \& M. J. Kenney (Eds.), Multicultural and gender equity in the mathematics classroom: The gift of diversity (pp. 81-91). Reston, VA: National Council of Teachers of Mathematics.

Garaway, G. B. (1994). Language, culture, and attitude in mathematics and science learning: A review of literature. Journal of Research and Development in Education, 27(2), 102-9.

Garrison, L., \& Mora, J. K. (2003). Adapting mathematics instruction for English language learners: The language-concept connection. In W. G. Secada, L. OrtizFranco, N. G. Hernandez, \& Y. De La Cruz (Eds.), Changing the faces of mathematics: Perspectives on Latinos (pp. 35-48). Reston, VA: National Council of Teachers of Mathematics.

Gay, A. S. (2008). Helping teachers connect vocabulary and conceptual understanding. Mathematics Teacher, 102(3), 218-223.

Gephart, Jr., R. P. (1988). Ethnostatistics: Qualitative foundations for quantitative research. Newbury Park, CA: Sage Publications.

Gibbons, P. (1998). Classroom talk and the learning of new registers in a second language. Language and Education, 12(2), 99-118.

Goldenberg, C. (2008). Teaching English language learners: What the research does - and does not - say. American Educator, 33(2), 8-19, 22-23, $42-44$.

Green, D. R. (1984). Talking of probability... Bulletin of the Institute of Mathematics and Its Applications, 20(9/10), 145-149.

Groth, R. E. (2008). Assessing teachers' discourse about the Pre-K-12 guidelines for assessment and instruction in statistics education (GAISE). Statistics Education Research Journal, 7(1), 16-39.

[Online: http://www.stat.auckland.ac.nz/ iase/serj/SERJ7(1)_Groth.pdf]

Hale, P. (2007). They know the math, but the words get in the way. Focus on Learning Problems in Mathematics, 29(1), 28-47. 
Halliday, M. A. K. (1975). Some aspects of sociolinguistics. In E. Jacobson (Ed.), Interactions between linguistics and mathematics education (pp. 64-73). Final report of the symposium sponsored by UNESCO, CEDO, and ICMI. Nairobi, Kenya, September 1-11, 1974. (UNESCO Report No. ED-74/CONE 808. Paris: UNESCO).

Hubbard, R. (1991). Teaching statistics to students who are learning in a foreign language. In D. Vere-Jones (Ed.), Proceedings of the Third International Conference on Teaching Statistics, Volume 1 (pp. 514-517). Voorburg, The Netherlands: International Statistical Institute.

[Online: http://www.stat.auckland.ac.nz/ iase/publications/18/BOOK1/C10-6.pdf]

Huberty, C. J. (2000). Judgment in quantitative research. The Mathematics Educator, 10(1), 5-10.

Johnson, A. (2010). Teaching mathematics to culturally and linguistically diverse learners. Boston: Pearson.

Kaplan, J. J., Fisher, D. G., \& Rogness, N. T. (2009). Lexical ambiguity in statistics: What do students know about the words association, average, confidence, random and spread? Journal of Statistics Education, 17(3).

[Online: http://www.amstat.org/publications/jse/v17n3/kaplan.html]

Kazima, M. (2007). Malawian students' meanings for probability vocabulary. Educational Studies in Mathematics, 64(2), 169-189.

Khisty, L. L. (1997). Making mathematics accessible to Latino students: Rethinking instructional practice. In J. Trentacosta \& M. J. Kenney (Eds.), Multicultural and gender equity in the mathematics classroom: The gift of diversity (pp. 92-101). Reston, VA: National Council of Teachers of Mathematics.

Konold, C., \& Pollatsek, A. (2002). Data analysis as the search for signals in noisy processes. Journal for Research in Mathematics Education, 33(4), 259-289.

Kotsopoulos, D. (2007). Mathematics discourse: It's like hearing a foreign language. Mathematics Teacher, 101(4), 301-305.

Lacelle-Peterson, M. W., \& Rivera, C. (1994). Is it real for all kids? A framework for equitable assessment policies for English language learners. Harvard Educational Review, 64(1), 55-75.

Lavy, I., \& Mashiach-Eizenberg, M. (2009). The interplay between spoken language and informal definitions of statistical concepts. Journal of Statistics Education, 17(1).

[Online: http://www.amstat.org/publications/JSE/v17n1/lavy.pdf]

Lee, O., \& Luykx, A. (2006). Science education and student diversity: Synthesis and research agenda. New York: Cambridge University Press.

Lesser, L. (2001). Representations of reversal: An exploration of Simpson's paradox. In A. Cuoco \& F. Curcio (Eds.), The roles of representation in school mathematics (pp. 129-145). Reston, VA: National Council of Teachers of Mathematics.

Lesser, L. (in press). Simple datasets for distinct basic summary statistics. Teaching Statistics.

Marín, G., \& Marín, B. V. O. (1991). Research with Hispanic populations [Applied social research methods series]. Newbury Park, CA: Sage Publications.

Martin, M. A. (2003). 'It's like ... you know': The use of analogies and heuristics in teaching introductory statistical methods. Journal of Statistics Education, 11(2). [Online: http://www.amstat.org/publications/jse/v11n2/martin.html]

Martynenko, G. (2003). Semiotics of statistics. Journal of Quantitative Linguistics, 10(2), 105-115.

McCoy, L. P., Buckner, S., \& Munley, J. (2007). Probability games from diverse cultures. Mathematics Teaching in the Middle School, 12(7), 394-402. 
Meaney, T. (2002). Symbiosis or cultural clash? Indigenous students learning mathematics. Journal of Intercultural Studies, 23(2), 167-187.

Mestre, J. (1986). Teaching problem solving strategies to bilingual students: What do research results tell us? International Journal of Mathematical Education in Science and Technology, 17(4), 393-401.

Mestre, J. P. (1988). The role of language comprehension in mathematics and problem solving. In R. R. Cocking \& J. P. Mestre (Eds.), Linguistic and cultural influences on learning mathematics (pp. 201-218). New Jersey: Lawrence Erlbaum Associates.

Mestre, J., Gerace, W. J., \& Lochhead, J. (1982). The interdependence of language and translational math skills among bilingual Hispanic engineering students. Journal of Research in Science Teaching, 19(5), 399-410.

Miles, M. B., \& Huberman, A. M. (1994). Qualitative data analysis: An expanded sourcebook (2nd ed.). Thousand Oaks, CA: Sage.

Mishra, P., \& Koehler, M. J. (2006). Technological pedagogical content knowledge: A new framework for teacher knowledge. Teachers College Record, 108(6), 1017-1054.

Moll, L. C. (1992). Bilingual classroom studies and community analysis: Some recent trends. Educational Researcher, 21(2), 20-24.

Moore, D. S. (1988). Should mathematicians teach statistics? The College Mathematics Journal, 19(1), 3-7.

Moschkovich, J. N. (2000). Learning mathematics in two languages: Moving from obstacles to resources. In W. Secada (Ed.), Changing faces of mathematics: Perspectives on multiculturalism and gender equity (pp. 85-93). Reston, VA: National Council of Teachers of Mathematics.

Moschkovich, J. N. (2002). A situated and sociocultural perspective on bilingual mathematics learners. Mathematical Thinking and Learning, 4(2/3), 189-212.

Moschkovich, J. N. (2003). Understanding the needs of Latino students in reform-oriented mathematics classrooms. In W. G. Secada, L. Ortiz-Franco, \& N. G. Hernandez (Eds.), Changing the faces of mathematics: Perspectives on Latinos (pp. 5-12). Reston, VA: National Council of Teachers of Mathematics.

Moschkovich, J. N. (2007). Using two languages when learning mathematics. Educational Studies in Mathematics, 64(2), 121-144.

Murrey, D. L. (2008). Differentiating instruction in mathematics for the English language learner. Mathematics Teaching in the Middle School, 14(3), 146-153.

National Council of Teachers of Mathematics (2000). Principles and standards of school mathematics. Reston, VA: Author.

National Council of Teachers of Mathematics (2008). NCTM position statement: Teaching mathematics to English language learners. NCTM News Bulletin, 45(5), 4.

Nolan, V. (2002). Influence of attitude towards statistics, English language ability and mathematical ability in the subject quantitative techniques at the Vaal Triangle Technikon, South Africa. In B. Phillips (Ed.), Proceedings of the Sixth International Conference on Teaching Statistics: Developing a statistically literate society, Cape Town, South Africa. [CD-ROM]. Voorburg, The Netherlands: International Statistical Institute.

[Online: http://www.stat.auckland.ac.nz/ iase/publications/1/8a5_nola.pdf]

Ortiz, J. J., Cañizares, M. J., Batanero, C., \& Serrano, L. (2002). An experimental study of probabilistic language in secondary school textbooks. In B. Phillips (Ed.), Proceedings of the Sixth International Conference on Teaching Statistics: Developing a statistically literate society, Cape Town, South Africa. [CD-ROM]. Voorburg, The Netherlands: International Statistical Institute.

[Online: http://www.stat.auckland.ac.nz/ iase/publications/1/10_25_ca.pdf] 
Pappamihiel, N. E., \& Mihai, F. (2006). Assessing English language learners' content knowledge in middle school classrooms. Middle School Journal, 39(1), 34-43.

Phillip, L., \& Wright, G. (1977). Cultural differences in viewing uncertainty and assessing probabilities. In H. Jungermann \& G. De Zeeuw (Eds.), Decision making and change in human affairs (pp. 507-519). Dordrecht: Reidel.

Pilar, R. (2003). Spanish-English language issues in the mathematics classroom. In W. G. Secada, L. Ortiz-Franco, \& N. G. Hernandez (Eds.), Changing the faces of mathematics: Perspectives on Latinos (pp. 23-34). Reston, VA: National Council of Teachers of Mathematics.

Rangecroft, M. (2002). The language of statistics. Teaching Statistics, 24(2), 34-37.

Rollnick, M. (1998). The influence of language on the second language teaching and learning of science. In W. W. Cobern (Ed.), Socio-cultural perspectives in science education (pp. 121-137). Dordrecht, Netherlands: Kluwer.

Rumsey, D. J. (2009). Teaching bits: Random thoughts on teaching. Journal of Statistics Education, 17(1).

[Online: http://www.amstat.org/publications/jse/v17n1/rumsey.html]

Santa Cruz, R. M. (2009). Giving voice to English language learners in mathematics. NCTM News Bulletin, 45(6), 4.

Santa Cruz, R. M., \& Sanchez-Gutiérrez, I. (2009). Supporting writing skills in English language learners. NCTM News Bulletin, 45(7), 4.

Schleppegrell, M. J. (2004). The language of schooling: A functional linguistics perspective. Mahwah, NJ: Lawrence Erlbaum Associates.

Shaughnessy, J. M. (1992). Research in probability and statistics: Reflections and directions. In D. A. Grouws (Ed.), Handbook of research on mathematics teaching and learning (pp. 465-494). New York: Macmillan.

Shuy, R. W. (1981). Conditions affecting language learning and maintenance among Hispanics in the United States. NABE Journal, 6, 1-18.

Siegel, M. A., Wissehr, C., \& Halverson, K. (2008). Sounds like success: A framework for equitable assessment - how to revise written assessments for English language learners. The Science Teacher, 75(3), 43-46.

Solano-Flores, G., \& Nelson-Barber, S. (2001). On the cultural validity of science assessments. Journal of Research in Science Teaching, 38(5), 553-573.

Sullivan, M. (2010). Statistics: Informed decisions using data. Upper Saddle River, NJ: Pearson.

Utts, J. M. (2005). Seeing through statistics (3rd ed.). Belmont, CA: Thomson Brooks/Cole.

Valverde, L. A. (1984). Underachievement and underrepresentation of Hispanics in mathematics and mathematics-related classes. Journal for Research in Mathematics Education, 15(2), 123-133.

Vogt, W. P. (2007). Quantitative research methods for professionals. Boston: Pearson.

Weisstein, E. W. (2009). Disjoint sets. From MathWorld - A Wolfram Resource.

[Online: http://mathworld.wolfram.com/DisjointSets.html]

Winsor, M. S. (2007). Bridging the language barrier in mathematics. Mathematics Teacher, 101(5), 372-378.

LAWRENCE M. LESSER

The University of Texas at El Paso

Department of Mathematical Sciences

500 W. University Avenue

El Paso, TX 79968-0514, USA 